\title{
Measurement of Cooling Effect of Building Environment Greening
}

\author{
Qinghai Luo, Jun Zou, Xiufei Yang
}

School of Urban Construction, University of South China, Hengyang, China.

Email: luoqinghai@126.com

Received February $17^{\text {th }}$, 2012; revised March $29^{\text {th }}$, 2012; accepted April $28^{\text {th }}, 2012$

\begin{abstract}
A series of measurements showed that community greening and trees shading had different degree of cooling effect. The cooling effect of wall greening was related to factors such as heat storage capacity and the orientation of the wall, climatic conditions. As compared to the heat reduced by sheltering the solar radiation, the heat absorbed by plant transpiration had greater cooling contribution. Comprehensive considering environment, technology and economics factors, the building district greening should take trees as the priority. The trees shading can significantly drop indoor temperature and temperature fluctuation, also created better condition for night-time natural ventilation.
\end{abstract}

Keywords: Wall Greening; District Greening; Trees Shading; Cooling Effect

\section{Introduction}

The building environment greening is the important mean to regulate the building microclimate and thermal environment. The building environment greening means the building body greening and ground greening in a certain range around the building, such as roof greening $[1,2]$, wall greening $[3,4]$, trees and lawns, which form the stereo greening landscape in the outdoor environment. The urban greening is the inevitable demand to construct the ecological civilization. Building greening is being paid close attentions to the energy saving and environmental benefit. There are some references for the evaluation of the benefit of building environment greening [5-7]. In this paper, the cooling effect of trees, lawns and water for building environment were measured and analyzed, which may be a reference for greening planning of urban and district, along with sustainable design of building.

\section{Cooling Effect of Wall Greening}

The coverage rate of parthenocissus heterrrphylla reached above $95 \%$ on west gable wall in a certain residential building in Hengyang city, China. Figure 1 shows the measurement dates of the cooling effect of parthenocissus heterrrphylla, on August 14, 2007.

The surface temperatures and of temperature variations of the greened wall and parthenocissus heterrrphylla are greatly dropped, as compared to that of bare wall and cement ground. The temperature of greened wall is lower than the weather temperature by $2.9^{\circ} \mathrm{C}$ $12^{\circ} \mathrm{C}$, and the temperature difference is more than $9.3^{\circ} \mathrm{C}$ in most times, by reducing the thermal effect of solar radiation on wall due to the good coverage and the strong transpiration. The temperature of green wall is lower than that of bare wall by $1.7^{\circ} \mathrm{C}-10.2^{\circ} \mathrm{C}$, and the temperature difference is more than $6.4^{\circ} \mathrm{C}$ in most times. The highest temperatures of weather, cement ground, bare wall, greened wall and plant surface were $39.2^{\circ} \mathrm{C}, 53.2^{\circ} \mathrm{C}$, $42.1^{\circ} \mathrm{C}, 32.5^{\circ} \mathrm{C}, 33.5^{\circ} \mathrm{C}$ respectively. It is beneficial to the thermal comfort and building energy saving due to decreasing indoor heat gain greatly by greening the west gable wall.

The cooling effect of wall greening came true mainly due to reducing the direct solar radiation by plant shelter and absorbing heat by plant transpiration. For the cooling effect, the contribution of the latter was greatly more significant than the one of the former. So the plants with strong photosynthesis and transpiration should be selected for wall greening. Applied to greening wall, the advantages of parthenocissus heterrrphylla was following: significantly cooling effect, increasing air humidity around the wall, along with strong adaptability and beautiful landscape, it is favorable to wall greening.

A series of measurements showed that the cooling effect of wall greening have related to factors such as heat storage capacity and the orientation of the wall, climatic conditions. The cooling effect of parthenocissus heterrrphylla was increased with solar radiation density and environment temperature, but decreased with environment 


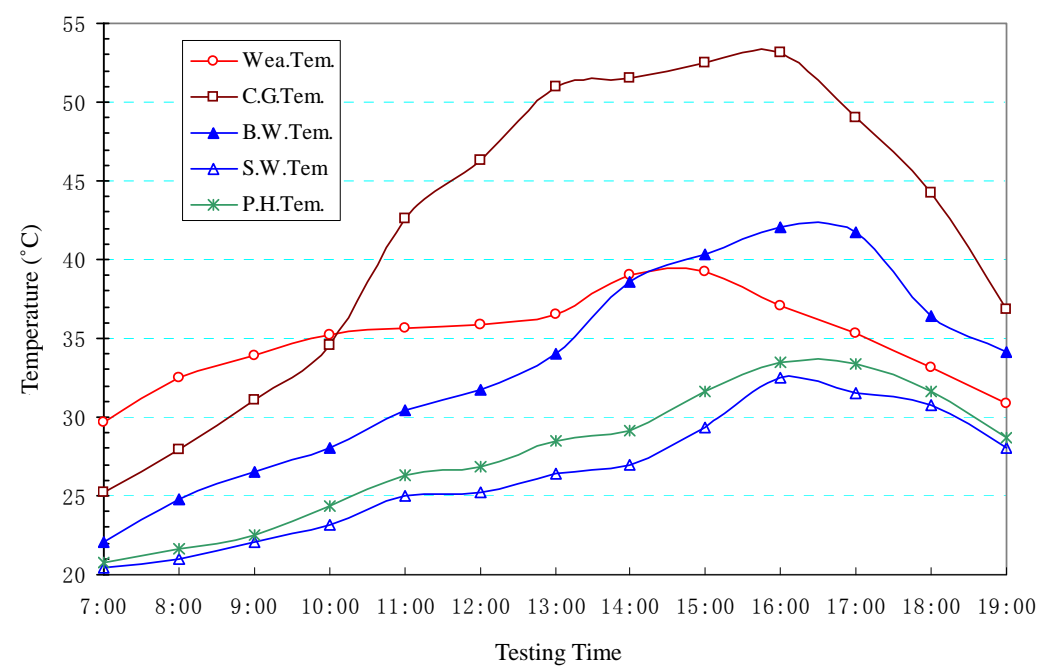

Figure 1. Cooling effect of west gable greening.

humidity. The wall with westward, direct solar radiation and excellent ventilation should be given prior consideration to wall greening. The influence order for the cooling effect of wall greening was as follows: solar radiation density $>$ environment temperature $>$ environment humidity.

\section{Cooling by District Greening}

The district greening may be included arbors, shrubs, lawns and flowers. The increasing demands on the beautifying and greening urban and districts is the inevitable to construct the ecological civilization. Figure 2 shows the measurement dates of the cooling effect by trees, lawns and wading pool for a residential community in Hengyang, China, on August 13, 2007. In the measurement, the levels of the thermometers are placed over the ground surface or water surface about $20 \mathrm{~cm}$.

A series of measurements showed that there were no cooling effect for trees, pools and lawns in cloudy and rainy days. The cooling effect were related to the amount and density of trees, the depth and scope of pools, the irrigation status of lawns, along with climatic conditions such as wind speed, air humidity and solar radiation intensity, etc.

According to the measurements of the cooling effect, comprehensive considering environment, technology and economics factors, the building district greening should take trees as the priority, and the main function of the lawns, flowers and pools may be beautification. The cooling effect of trees was significant, the growth period was long, the life force was strong and the maintaining workload was less after surviving. The advantages also include conserving soil and water, windbreak and sand fixation, decreasing noise, purifying air, sustaining the humidity and conserving the underground water in the urban. The cooling effects of the shrubs and lawns were not significant, with the disadvantages of many diseases and insects, and high management cost. Pools take high construction and operating cost, along with abundance of water consumption. Taking the trees as the leading factor for greening, the vertical greening can be achieved for the ground and different levels. Besides, the trees can provide a leisure location for inhabitant and a convenient habitat for birds and insects; also cultivate biology diversity in the distinct.

\section{Tree Shading Cooling}

Figure 3 shows the measurement data of the cooling effects of camphor tree shading on the indoor thermal environment. The measurement was performed in a laboratory building in University of south China in Hengyang. China on July, 2008. The laboratory building is a two-storey building with brick-concrete structure. The measurement was performed in room A and room B. Both are top floors, with the identical area, orientation and layout. Their functions were basically same. The two rooms were separated by two laboratory rooms with the similar functions. There was no tree shading around the room $\mathrm{A}$, while a coverage rate of camphor trees is about $70 \%$ around room B. Measurements data of outdoor temperature (Outdoor), indoor temperature of room $\mathrm{A}$ (Room A) and indoor temperature of room B (Room B) were detailed in Figure 3.

As shown in Figure 3, the indoor thermal environment can be improved significantly by tree shading. The effects were mainly as follows: 1 ) The indoor temperature of room $\mathrm{B}$ was lower than that of room $\mathrm{A}$ by $2^{\circ} \mathrm{C}-3^{\circ} \mathrm{C}$. When the highest outdoor temperature reached $39.4^{\circ} \mathrm{C}$, the ones were $35.6^{\circ} \mathrm{C}$ and $32.5^{\circ} \mathrm{C}$ respectively in room $\mathrm{A}$ and room B. 2) The temperature fluctuation in room B 


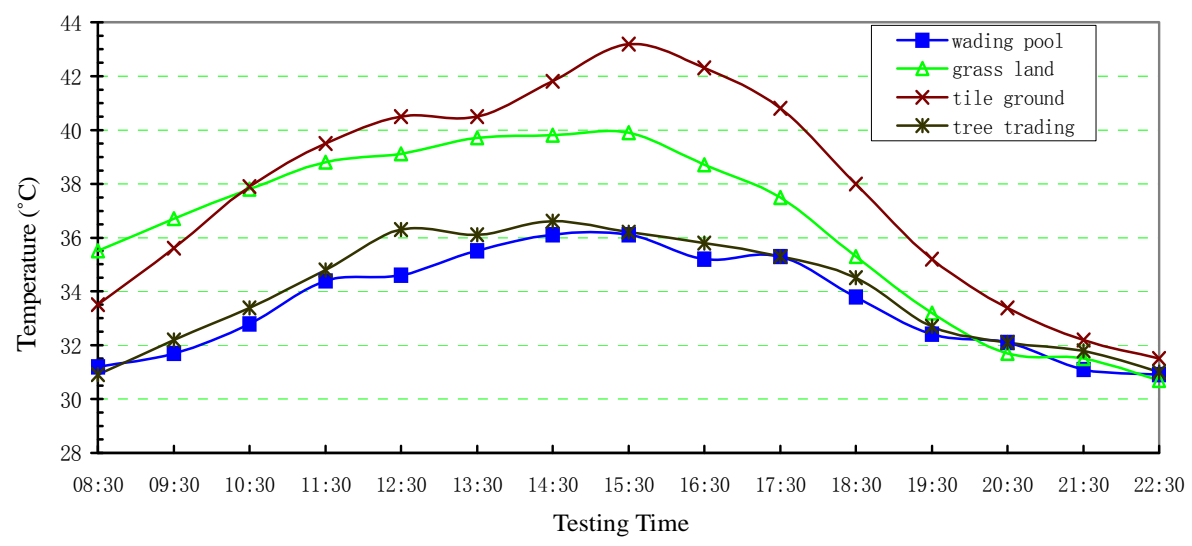

Figure 2. Measurement data of cooling effect of trees, lawns and wading pool.

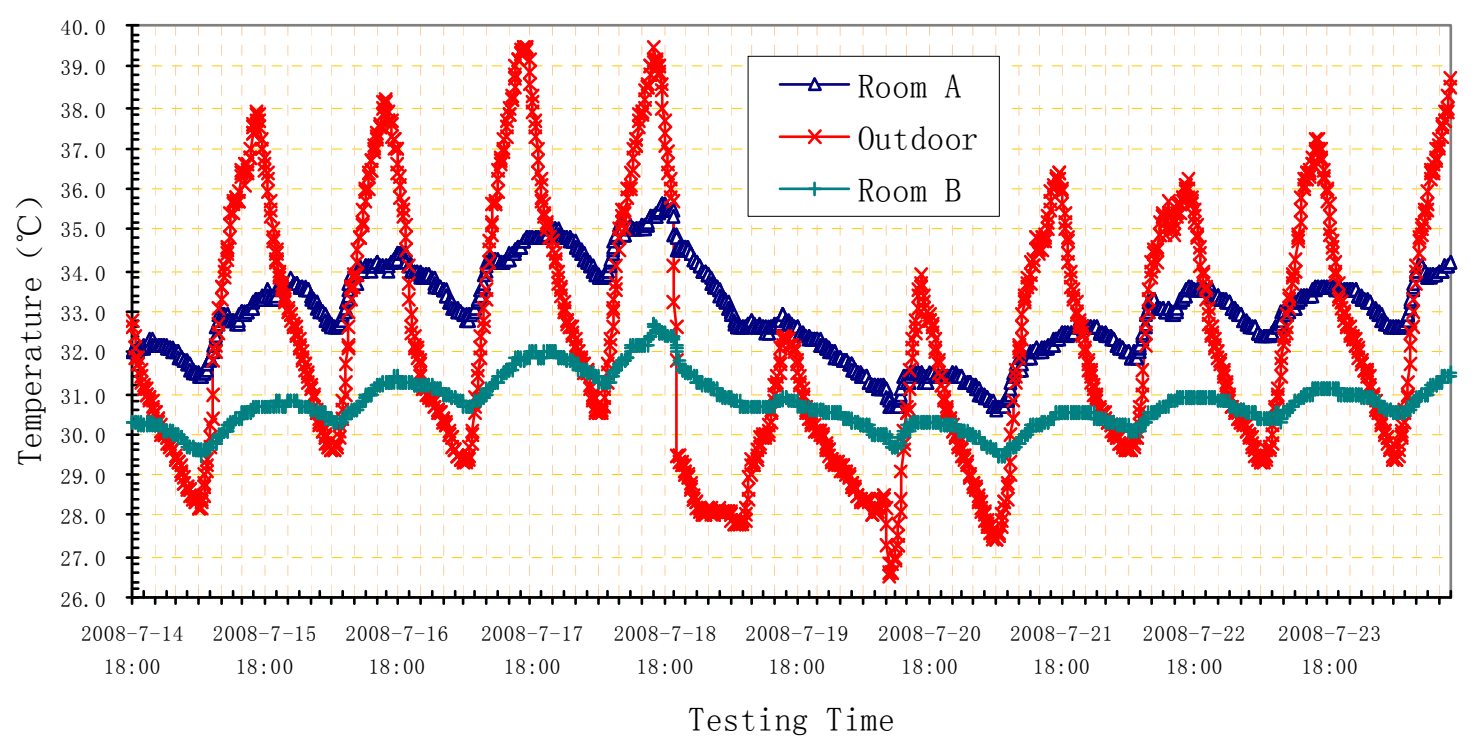

Figure 3. Effect of camphor tree on the indoor thermal environment.

was smaller than that in room $\mathrm{A}$. the highest temperature fluctuation was $2.1^{\circ} \mathrm{C}$ and $1.2^{\circ} \mathrm{C}$ of $24 \mathrm{~h}$ period respecttively in room A and room B. 3) The peak temperature in room B was delayed than that in room A. During the experimental period, the peak temperature in room B relative to outdoor temperature was delayed by 90 - 150 minutes, while by 50 - 100 minutes for room A. So the tree shading may create a better condition for night-time natural ventilation.

It was an important and effective way to obtain a good indoor thermal environment by reasonable controlling solar radiation absorbed by the buildings. The wall heat transfer was the main factor of indoor heat gain in summer. Due to tree shading, not only the direct influences of solar radiation on the enclosure structure can be decreased, but also the indoor thermal environment can be improved The energy consumption of air-condition was reduced and then the building energy consumption was saved. Besides, it is of significance to reduce the thermal island intensity, to improve the urban environment and to boost the urban ecological civilization.

\section{Conclusions}

Greening building body, via plant shading, insulation and photosynthesis, the solar radiation can be transformed into other energy form, besides, via plant transpiration, microenvironment energy can be absorbed and the environment temperature can be dropped, thus, the virtuous circle of energy may be reached.

Comprehensive considering environment, technology and economics factors, the building district greening should take trees as the priority, and the main function of the lawns, flowers and pools may be beautification. The advantages of trees are as follows: significant cooling effect, less maintenance and management, benefit to the ecological diversity and to harmony between man and 
nature, along with improving the level of ecological civilization of city and district environment.

The trees shading can significantly improve indoor thermal environment, namely, drop indoor temperature and temperature fluctuation, also created better condition for night-time natural ventilation, besides, other environmental benefits can be obtained.

\section{REFERENCES}

[1] R. Kumar and S. C. Kaushik, "Performance Evaluation of Green Roof and Shading for Thermal Protection of Buildings,” Building and Environment, Vol. 40, No. 11, 2005, pp. 1505-1511. doi:10.1016/j.buildenv.2004.11.015

[2] M. Tang, Z. Yang and L. Li, “Thermal Insulation Characteristics of Green Roofs in Natural State," Heating Ventilating \& Air Conditioning, Vol. 37, No. 3, 2007, pp. 1-5.
[3] X. Chen and X. Zhang, "Study on Effect of Decreasing Temperature and Increasing Humidity of Metope Greening by Sedum Lineare," Journal of Anhui Agricultural Sciences, Vol. 36, No. 28, 2008, pp. 12163-12164 .

[4] Y. Li and Q. Shi, "Research on Decreasing Temperature and Increasing Relative Humidity of Housing Wall Greening,” Meteorological and Environmental Sciences, Vol. 30, No. 1, 2007, pp. 23-25.

[5] S. Li, Y. Zhao, X. Li, et al., "Effect of Urban Forests on Heat pollution and Comfortable Degree of Human Body," Journal of Agriculture University of Henan, Vol. 29, No. 1, 1995, pp. 11-18.

[6] J. Zhao, X. Ma and Y. Xiao, "CFD Simulation of the Indoor Thermal Environment of Building Surface Planting,” Fluid Machinery, Vol. 35, No. 6, 2007, pp. 5-80.

[7] X. Gao, S. Jin and Y. Qu, "Research on the Impact of Green Roof on Indoor Human Thermal Comfort," Journal of Chongqing Jianzhu University, Vol. 29, No. 5, 2007, pp. 44-49. 